\title{
7. A matrícula em disciplinas na UFABC
}

\author{
Aline Guarnieri Gubitoso \\ Vinicius Cifú Lopes
}

\section{SciELO Books / SciELO Livros / SciELO Libros}

GUBITOSO, G., and LOPES, V. C. A matrícula em disciplinas na UFABC. In: Alocações, estabilidade e otimização: uma introdução passo a passo [online]. São Bernardo do Campo, SP: Editora UFABC, 2017, pp. 123-136. ISBN: 978-85-6857-682-3. https://doi.org/10.7476/9788568576823.0008.

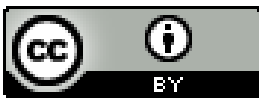

All the contents of this work, except where otherwise noted, is licensed under a Creative Commons Attribution 4.0 International license.

Todo o conteúdo deste trabalho, exceto quando houver ressalva, é publicado sob a licença Creative Commons Atribição $\underline{4.0}$.

Todo el contenido de esta obra, excepto donde se indique lo contrario, está bajo licencia de la licencia $\underline{\text { Creative }}$ Commons Reconocimento 4.0. 


\section{A matrícula em disciplinas na UFABC}

\section{Siglas utilizadas:}

UFABC: Universidade Federal do ABC

ConsEPE: Conselho de Ensino, Pesquisa e Extensão da UFABC CP: Coeficiente de progressão no bacharelado interdisciplinar $\mathrm{CP}_{\mathrm{k}}$ : $\quad$ Coeficiente de progressão no curso de formação específica CR: $\quad$ Coeficiente de rendimento

ProGrad: Pró-reitoria de Graduação da UFABC

Com base em seu sucesso no cotidiano como a alocação de alunos em escolas, propomos aplicar o algoritmo Gale-Shapley ao processo de matrícula dos alunos nas disciplinas da graduação da Universidade Federal do ABC (UFABC). Primeiramente, devemos entender como o processo de alocação de cada aluno em turmas de várias disciplinas ocorre atualmente na instituição.

É preciso atentar para o significado preciso dos termos disciplina e turma. A disciplina é um volume de conhecimento a ser coberto em um ciclo letivo e é comumente conhecida como "matéria" ou "curso", embora um curso seja uma formação de vários ciclos e disciplinas (bacharelado, licenciatura etc.). A turma, ou "sala", identifica o local, os horários, o ministrante e o grupo de alunos envolvidos nessa realização da disciplina. 


\subsection{0 método contemporâneo}

Todo ano, os coordenadores dos cursos planejam as disciplinas que serão ofertadas nos três quadrimestres letivos, sendo que, especificamente em cada quadrimestre, eles comunicam se houve alguma mudança. Tais dados são lançados no sistema chamado "de associação", que tem como função alimentar um outro sistema, o "de alocação", o qual aloca as disciplinas ofertadas em salas de aula (primeiro as disciplinas que utilizam os laboratórios e, depois, as que ocorrem em salas). Com tal combinação, as turmas são criadas para, então, serem estipuladas a quantidade de vagas e horários que cada turma de determinada disciplina terá, segundo a escolha dos coordenadores de cada curso.

Uma vez que as turmas são formadas e estabelecidas no sistema de alocação, este é vinculado a um terceiro sistema, denominado "de matrículas", que, em época de matrícula (durante o quadrimestre anterior ao qual os alunos irão se matricular), libera o acesso dos alunos, por um tempo determinado, aos dados e turmas disponíveis para que esses alunos possam matricular-se nas turmas das disciplinas que desejam cursar.

Neste sistema, as disciplinas estão organizadas em ordem alfabética segundo o bacharelado a que pertencem (interdisciplinar ou específico) e são listados o código, nome, turma e horário da disciplina, assim como o número máximo de vagas e quantos estudantes já se inscreveram nessa turma. Entretanto, um estudante pode escolher turmas que já têm o número máximo de inscritos, uma vez que o processo de escolha e eliminação é feito depois que todos se matricularam, de modo que a ordem de chagada não interfira na matrícula.

Simultaneamente às matrículas que o aluno está fazendo, o próprio sistema verifica o número de créditos em que esse aluno está se matriculando, uma vez que cada aluno tem um número máximo de créditos que pode cursar de acordo com o seu CR (resolução ConsEPE $n^{0}$ 131). Além disso, o sistema verifica se, por algum erro, o aluno não se matriculou em horários conflitantes ou em 
disciplinas iguais de turmas ou horários diferentes, de forma que, se algum desses conflitos ou limites forem transgredidos, o sistema impede a conclusão da matrícula do aluno.

Todos os alunos podem modificar suas escolhas quantas vezes quiserem enquanto o sistema estiver aberto, porém quando o período de matrícula termina, o sistema não permite mais o acesso, e, consequentemente, a matrícula dos alunos. Seus pedidos de matrículas são, então, enviados aos coordenadores de cada curso, que analisam tais dados a fim de verificar a necessidade de modificações, como, por exemplo, de eliminação de turmas, aumento de vagas ou criação de novas turmas. Esse ajuste é informado à ProGrad, que reconfigura todos os sistemas citados anteriormente, de modo que as modificações sejam incluídas no sistema de matrículas.

Nas turmas com mais matrículas do que vagas, determinam-se quais alunos têm seu pedido atendido segundo critérios específicos para cada tipo de disciplina: nas disciplinas obrigatórias dos bacharelados interdisciplinares (no quadrimestre ideal), aqueles alunos com turno de entrada correspondente e melhor CR, e, nas demais disciplinas, aqueles alunos com turno de entrada correspondente, reserva de vaga e melhor $\mathrm{CP}_{\mathrm{k}}$ (resolução ConsEPE n ${ }^{\circ} 31$ ).

Assim, cada turma tem, pelo sistema, uma relação dos nomes dos alunos matriculados, sendo que cada um deles tem suas informações (se tem a reserva de vaga, o turno, CR, CP, dentre outros) analisadas pela ProGrad manualmente segundo os critérios acima.

A partir desses dados, a ProGrad disponibiliza as matrículas indeferidas, isto é, disciplinas em que os alunos não conseguiram se matricular. Em seguida, somente os alunos com matrículas indeferidas têm acesso ao sistema de matrículas novamente, no período denominado "ajuste", em que se matriculam em outras disciplinas ou turmas no lugar daquelas em que não conseguiram ser admitidos. Porém, as matrículas bem-sucedidas na etapa anterior continuam alocadas. Nesta etapa do processo, o critério para a aprovação da matrícula é a ordem de chegada.

Depois, ocorre um segundo período de ajuste, no qual agora se permite o acesso de todos os alunos para que tenham a chance de, se 
desejarem ou tiverem a necessidade, modificar alguma das turmas em que se matricularam. Mais uma vez, a ordem de preferência pelas vagas em cada turma é determinada pela ordem de chegada de cada aluno; também ocorre a inclusão de novas disciplinas criadas anteriormente pelos coordenadores de curso, a fim de que todos os alunos tenham as mesmas chances de selecioná-las. Quando esse sistema fecha o acesso aos alunos, encerram-se os períodos de matrícula e ajuste para o quadrimestre seguinte.

Destacamos que a primeira matrícula dos ingressantes ocorre para seu segundo quadrimestre (no primeiro quadrimestre, todos os alunos foram inscritos pela ProGrad), ainda na vigência do primeiro quadrimestre, quando os alunos não possuem CP ou CR. Por isso, a ProGrad determina que, no sistema de matrícula, esses alunos tenham reserva de vagas nas disciplinas que seriam obrigatórias a eles em seu segundo quadrimestre. É permitido que esses alunos, no ajuste, também selecionem outras disciplinas.

Antes de ser estabelecido esse método de matrícula, e como não havia sistema informatizado, a UFABC realizava o processo de matrícula manualmente, dado que eram poucos alunos e disciplinas na universidade: somente 15 turmas em 2007, comparando-se a aproximadamente 900 em 2014. Além disso, não era necessário eliminar matrículas devido à pequena quantidade de alunos.

\subsection{Nossa proposta}

A automação do sistema de matrícula da UFABC é um tópico de pesquisa industrial, tanto no desenvolvimento de uma solução algorítmica, como na sua implementação informatizada. Nosso objetivo é aproveitá-lo como exemplo das ideias que apresentamos neste livro e como motivação para o leitor realizar adaptações a suas próprias questões.

Nesta seção, propomos um procedimento simplificado para a matrícula, que utiliza o algoritmo de Gale-Shapley (na versão adequada para o "problema das admissões em universidades"). Sem 
dúvida, uma implementação experimental e desenvolvimentos posteriores poderão sanar dificuldades não consideradas aqui. Seguiremos a explanação com um exemplo diminuto.

A proposta não contempla diversas normas da UFABC com respeito a reservas de vagas ou limites de carga horária, embora essas normas possam ser oportunamente observadas em um programa mais detalhado. A esse respeito, somente assumiremos que (a) sejam ofertadas vagas e turmas em número suficiente e horários compatíveis para atender à demanda regular das disciplinas e que (b) haja uma classificação final entre alunos, para ser utilizada como lista de preferência da universidade, potencialmente obtida dos coeficientes de rendimento e progressão e variada entre disciplinas.

Por outro lado, fazemos uso explícito de uma distinção do plano pedagógico da instituição: a liberdade do aluno em cursar disciplinas de sua escolha e na ordem e na quantidade que quiser, embora haja matrizes curriculares recomendadas e requerimentos para a obtenção dos graus disponíveis. Enquanto é essa liberdade (e consequente imprevisibilidade) que torna o sistema de matrículas da UFABC um problema complexo, vemo-la também como uma possibilidade para sua solução.

Nossa proposta é que o aluno especifique uma ordem de preferência entre as disciplinas que deseja cursar, podendo dar preferência a uma disciplina que necessita para colação de grau, ou a um conteúdo com o qual tem mais dificuldade, ou a um assunto favorito etc. Essa ordenação não deve ser relevante no cumprimento das matrizes ideais, conquanto haja oferta suficiente e compatível de vagas e horários.

Primeira Etapa - coleta das informações dos alunos

No período de matrícula, um formulário eletrônico deverá ser disponibilizado aos alunos. Após login com identificação e senha, será exibida uma primeira página com listas de opções, pedindo: "Selecione sua primeira disciplina, em ordem de prioridade". Após a seleção, a página identificará as turmas oferecidas (com local, horários, ministrante etc.), pedindo: "Selecione sua $1^{a}$ opção de turma"; 
"Selecione sua $2^{\mathrm{a}}$ opção de turma"; "Selecione sua $3^{\mathrm{a}}$ opção de turma"; ... sem limitação do número de opções.

Concluída essa seleção, será exibida uma página semelhante, pedindo pela seleção da segunda disciplina e, então, as seleções das turmas oferecidas como $1^{\mathrm{a}}$ opção, $2^{\mathrm{a}}$ opção, $3^{\mathrm{a}}$ opção etc.

O processo será repetido para quantas disciplinas o aluno tiver interesse, bloqueando, em cada caso, a escolha de disciplinas ou turmas já escolhidas.

Segunda Etapa - aplicação do algoritmo

Para compreensão desta etapa, observamos que as disciplinas serão tratadas em ordem de preferência: inicialmente, a disciplina colocada em primeiro por cada aluno, como se ele houvesse escolhido somente essa disciplina (ainda que alunos diferentes escolham disciplinas diferentes), depois a disciplina colocada em segundo e assim por diante.

Para $n$ de 1 em diante:

- listamos as opções de preferência de turma de cada aluno, referentes à sua $n$-ésima escolha de disciplina;

- emparelhamos alunos e turmas segundo essas opções de preferência, segundo Gale-Shapley, com os alunos propondo às turmas (que têm suas listas de preferência providas pela instituição);

- para cada aluno que tenha tido uma turma alocada, eliminamos as opções de turmas para suas disciplinas escolhidas subsequentemente - a $(n+1)$-ésima, a $(n+2)$-ésima etc. - cujos horários conflitam com o da turma alocada.

Em vista do último passo, é importante que o aluno já escolha horários compatíveis entre turmas ou identifique um número suficiente de turmas para cada disciplina, para que encontre vaga em horário compatível.

Note que, no primeiro passo, as vagas de uma determinada disciplina não devem ser imediatamente esgotadas, exceto se o total de 
alunos (para os quais se criem vagas) já a selecione imediatamente como prioridade. É praticamente certo, porém, que os alunos que identificarem uma disciplina com mais prioridade esgotem as vagas das turmas mais cobiçadas dessa disciplina. Após o exemplo, relatamos outras observações.

Exemplo: Trabalharemos com cinco alunos $A, B, C, D$ e $E$; três disciplinas $X, Y$ e $Z$; duas turmas de cada disciplina, identificadas com os índices $D$ e $N$; cada turma com duas vagas; e dois conflitos de horário, $X_{D} \operatorname{com} Z_{D}$ e $X_{N} \operatorname{com} Y_{N}$.

Por exemplo, o aluno $A$ determina sua lista de preferência da seguinte forma: ele considera prioritário conseguir se matricular na disciplina $X$, da qual prefere a turma $X_{N}$ à turma $X_{D}$. Depois, considera cursar a disciplina $Z$, preferindo a turma $Z_{N}$ à turma $Z_{D}$, e, por fim, escolhe cursar a disciplina $Y$, preferindo a turma $Y_{N}$ à turma $Y_{D}$. Sendo assim:

$$
\begin{array}{llll}
A: & 1^{\text {a }}: & X: & X_{N}>X_{D} \\
& 2^{\text {a: }} & Z: & Z_{N}>Z_{D} \\
& 3^{\text {a }}: & Y: & Y_{N}>Y_{D}
\end{array}
$$

Enquanto isso, o aluno $B$, ao fazer sua própria lista, ordena cada disciplina de modo que escolhe como sua prioridade a disciplina $X$, sendo que prefere a turma $X_{D}$ à turma $X_{N}$ Em seguida, deseja se matricular na disciplina $Y$, tendo preferência pela turma $Y_{N}$ à turma $Y_{D}$. Sua terceira escolha de disciplina é, então, a disciplina $Z$, que prefere cursar na turma $Z_{N}$ e, depois, na turma $Z_{D}$. Ou seja:

$$
\begin{array}{llll}
B: & 1^{\text {a }}: & X: & X_{D}>X_{N} \\
& 2^{\text {a: }}: & Y: & Y_{N}>Y_{D} \\
& 3^{\text {a }}: & Z: & Z_{N}>Z_{D}
\end{array}
$$

Dessa forma, seguem-se as listas de preferência de cada aluno pelas turmas ofertadas: 


\begin{tabular}{|c|c|c|c|}
\hline \multirow[t]{3}{*}{$A:$} & $1^{\mathrm{a}}:$ & $X:$ & $X_{N}>X_{D}$ \\
\hline & $2^{\mathrm{a}}:$ & $Z:$ & $Z_{N}>Z_{D}$ \\
\hline & $3^{\mathrm{a}}:$ & $Y:$ & $Y_{N}>Y_{D}$ \\
\hline \multirow[t]{3}{*}{$B:$} & $1^{\mathrm{a}}:$ & $X:$ & $X_{D}>X_{N}$ \\
\hline & $2^{\mathrm{a}}:$ & $Y:$ & $Y_{N}>Y_{1}$ \\
\hline & $3^{\mathrm{a}}:$ & $Z:$ & $Z_{N}>Z_{D}$ \\
\hline \multirow[t]{3}{*}{$C:$} & $1^{\mathrm{a}}:$ & $Y:$ & $Y_{N}>Y_{D}$ \\
\hline & $2^{\mathrm{a}}:$ & $X:$ & $X_{N}>X_{D}$ \\
\hline & $3^{\mathrm{a}}:$ & $Z:$ & $Z_{D}>Z_{\Lambda}$ \\
\hline \multirow[t]{3}{*}{$D:$} & $1^{\mathrm{a}}:$ & $X:$ & $X_{D}>X_{N}$ \\
\hline & $2^{\mathrm{a}}:$ & $Z:$ & $Z_{D}>Z_{N}$ \\
\hline & $3^{\mathrm{a}}:$ & $Y:$ & $Y_{D}>Y$ \\
\hline \multirow[t]{3}{*}{$E:$} & $1^{\mathrm{a}}:$ & $X:$ & $X_{D}>X_{N}$ \\
\hline & $2^{\mathrm{a}}:$ & $Y:$ & $Y_{N}>Y$ \\
\hline & $3^{\mathrm{a}}:$ & $Z:$ & $Z_{N}>$ \\
\hline
\end{tabular}

Ao passo que a universidade tem sua própria classificação dos alunos, em conformidade com os dados de todos os alunos da instituição em determinado critério (média de notas etc.). A título de exemplo, indicamos uma classificação uniforme para todas as turmas:

Classificação dos alunos: $D>A>B>E>C$

O próximo passo é a proposta dos alunos à disciplina de sua primeira escolha: $A, B, D, E$ deverão ser emparelhados com as turmas da disciplina $X$, enquanto $C$ deve ser emparelhado com as turmas da disciplina $Y$. Formamos, então, as seguintes listas de preferência para utilizarmos o algoritmo de Gale-Shapley: 

A: $\quad X_{N}>X_{D}$
$B: \quad X_{D}>X_{N}$
C: $\quad Y_{N}>Y_{D}$
D: $\quad X_{D}>X_{N}$
E: $\quad X_{D}>X_{N}$

\section{$1^{\text {a }}$ Rodada da alocação da primeira disciplina}

$$
A m X_{N^{\prime}}, B m X_{D^{\prime}}, C w Y_{N^{\prime}} D m X_{D^{\prime}} E m X_{D}
$$

Com esta primeira rodada, $A$ propõe à turma $X_{N}$, que, por ter vagas disponíveis, aceita sua matrícula. O mesmo acontece com $C$, que propõe a $Y_{N}$. Entretanto, $B, D$ e $E$ escolhem todos propor à turma $X_{D}$, de modo que, por haver mais solicitações do que vagas disponíveis, a universidade utiliza o critério de classificação dos alunos. Sendo assim, $B$ e $D$ conseguem matricular-se nesta turma, enquanto $E$ é rejeitado na rodada:

$$
X_{D}-\{B, D\}, X_{N}-A, Y_{N}-C
$$

\section{$2^{\text {a }}$ Rodada da alocação da primeira disciplina}

$$
E m X_{N}
$$

$\mathrm{Na}$ rodada seguinte, os alunos que não foram alocados em nenhuma turma serão alocados à sua opção subsequente de turma preterida da primeira disciplina escolhida. Por isso, $E$ propõe à sua segunda opção, a turma $X_{N}$, que aceita sua matrícula por ter vagas disponíveis:

$$
X_{D}-\{B, D\}, X_{N}-\{A, E\}, Y_{N}-C
$$

Note que realizamos uma execução completa do algoritmo Gale-Shapley, o que finaliza a alocação nas disciplinas de prioridade 
mais alta dos alunos. Durante essa execução, poderia ter havido "troca" de alunos em uma turma, caso uma turma já completada "preferisse" um aluno novo aos que já tem; isso apenas não ocorreu no exemplo. Porém, entre diferentes execuções, os alunos já matriculados não serão rejeitados, como veremos na última alocação.

Agora é preciso excluir, nas listas de preferências dos alunos (da segunda disciplina em diante), as turmas cujos horários conflitam com a primeira turma alocada a cada aluno. Também é preciso diminuir o número de vagas das turmas parcialmente preenchidas e excluir as turmas que já estão com todas as suas vagas preenchidas (embora viole o princípio dos melhores classificados em cada turma). Assim, nas listas de $C$ são excluídas as turmas $X_{N}$ e $X_{D}$ (já preenchidas); nas listas de $D$ é excluída a turma $Z_{D}$ (em conflito com $X_{D}$ ); nas listas de $E$ é excluída a turma $Y_{N}$ (em conflito $\operatorname{com} X_{N}$ ). Note que $C$, então, tem sua $2^{a}$ lista original esvaziada e substituída imediatamente pela $3^{\mathrm{a}}$ (cf. exercício ao final do exemplo). A turma $Y_{N}$ passa a ter uma única vaga, porque já tem $C$ matriculado.

$$
\begin{array}{llll}
A: & 2^{\text {a }}: & Z: & Z_{N}>Z_{D} \\
& 3^{\text {a }}: & Y: & Y_{N}>Y_{D} \\
B: & 2^{\text {a }}: & Y: & Y_{N}>Y_{D} \\
& 3^{\text {a }}: & Z: & Z_{N}>Z_{D} \\
C: & \text { “" } 2^{\text {a” }} & Z: & Z_{D}>Z_{N} \\
D: & 2^{\text {a }}: & Z: & Z_{N} \\
& 3^{\text {a }}: & Y: & Y_{D}>Y_{N} \\
E: & 2^{\text {a }}: & Y: & Y_{D} \\
& 3^{\text {a }:} & Z: & Z_{N}>Z_{D}
\end{array}
$$

Em seguida, iniciam-se as propostas dos alunos às turmas das segundas disciplinas escolhidas, também por Gale-Shapley, com estas listas de preferência: 

$A: \quad Z_{N}>Z_{D}$
B: $\quad Y_{N}>Y_{D}$
C: $\quad Z_{D}>Z_{N}$
$D: \quad Z_{N}$
$E: \quad Y_{D}$

\section{Alocação da segunda disciplina}

$$
A m Z_{N}, B \cdots Y_{N}, C w Z_{D}, D m Z_{N}, E m Y_{D}
$$

No processo de alocação da segunda disciplina, todos os alunos conseguem ser matriculados logo na primeira opção remanescente, lembrando que $C$, na verdade, não é matriculado na disciplina $X$ que era sua segunda prioridade original. Obtemos:

$$
Y_{D}-E, Y_{N}-\left\{C_{\text {anterior }}, B\right\}, Z_{D}-C, Z_{N}-\{A, D\}
$$

Com o fim da segunda etapa, é necessário que novamente sejam excluídas as opções de turmas nas disciplinas seguintes (aqui só havendo a terceira disciplina de cada aluno) que conflitam com as turmas já alocadas aos alunos ou já fechadas (sem vagas). Desse modo, a turma $Y_{N}$ é excluída das listas de $A$ e $D$, enquanto a turma $Z_{N}$ é excluída das listas de $B$ e $E$, por não terem mais vagas disponíveis. A turma $Z_{D}$ passa a ter uma única vaga. $O$ aluno $C$ já não tem mais disciplinas em sua lista. Restam estas preferências:

$\begin{array}{llll}A: & 3^{\text {a }} & Y: & Y_{D} \\ B: & 3^{\text {a }}: & Z: & Z_{D} \\ D: & 3^{\text {a }}: & Y: & Y_{D} \\ E: & 3^{\text {a }}: & Z: & Z_{D}\end{array}$

Rodadas da alocação da terceira disciplina

$$
A m Y_{D}, B \cdots Z_{D}, D m Y_{D}, E m Z_{D}
$$


$A$ e $D$ propõem a $Y_{D}$, mas ao haver somente uma vaga disponível naturma, a universidade escolhe alocar $D$, por ser melhor aluno segundo o critério determinado para a preferência entre os alunos. Note que $E$ mantém sua vaga em $Y_{D}$, em detrimento de $A$, porque a selecionou anteriormente. Entre $B$ e $E$ a mesma situação ocorre, pois ambos propõem a mesma turma, $Z_{D}$, que já contém $C$. Deste modo, por haver uma vaga disponível na turma, a universidade escolhe o melhor aluno B. Obtemos:

$$
Z_{D}-\left\{C_{\text {anterior }}, B\right\}, Y_{D}-\left\{E_{\text {anterior }}, D\right\}
$$

Como havia três disciplinas na lista de prioridade de cada aluno, executamos o algoritmo de Gale-Shapley três vezes e o procedimento proposto está completo. Obtivemos como resultado as seguintes alocações, que podem ser vistas em dois formatos:

\begin{tabular}{l} 
matrículas dos alunos \\
\hline$A-\left\{X_{N}, Z_{N}\right\}$ \\
$B-\left\{X_{D}, Y_{N}, Z_{D}\right\}$ \\
$C-\left\{Y_{N}, Z_{D}\right\}$ \\
$D-\left\{X_{D}, Y_{D}, Z_{N}\right\}$ \\
$E-\left\{X_{N}, Y_{D}\right\}$
\end{tabular}

\section{listas de presença}

$$
\begin{aligned}
& X_{D}-\{B, D\} ; \\
& X_{N}-\{A, E\} ; \\
& Y_{D}-\{D, E\} ; \\
& Y_{N}-\{B, C\} ; \\
& Z_{D}-\{B, C\} ; \\
& Z_{N}-\{A, D\} ;
\end{aligned}
$$

\section{Exercício}

1) Refaça as alocações acima sem adiantar a matrícula de $C$ na eta-

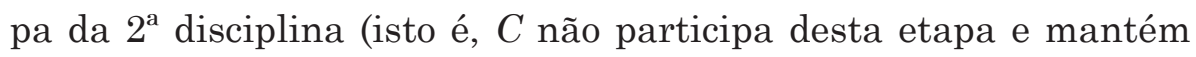
a lista $Z_{D}>Z_{N}$ para a terceria etapa) e verifique que a solução é alterada, tanto em sua matrícula como na dos colegas.

Resposta: Uma vaga em $Z_{D}$ passa de $C$ para $E$. Isso mostra que regras claras precisam ser refletidas nas especificações de um algoritmo. A alocação completa fica: 
matrículas dos alunos

$A-\left\{X_{N}, Z_{N}\right\}$;

$B-\left\{X_{D}, Y_{N}, Z_{D}\right\}$;

$C-Y_{N}$

$D-\left\{X_{D}, Y_{D}, Z_{N}\right\}$;

$E-\left\{X_{N}, Y_{D}, Z_{D}\right\}$; listas de presença

$X_{D}-\{B, D\}$;

$X_{N}-\{A, E\}$;

$Y_{D}-\{D, E\}$;

$Y_{N}-\{B, C\}$;

$Z_{D}-\{B, E\}$;

$Z_{N}-\{A, D\}$;

Observações: Este problema é muito semelhante ao de casais de estudantes na residência médica, como explicamos na Seção 5.4, com a consideração de que um aluno pode pleitear matrícula em várias disciplinas. No todo, portanto, não deve ter soluções estáveis e deve ser computacionalmente complexo.

Nossa solução é a mesma adotada pelo NIMP para casais até 1982, com a seleção de uma disciplina "líder" e outras em ordem de prioridade, e oferece a mesma razão para o surgimento de instabilidades: talvez uma turma considerada um pouco pior para a primeira disciplina tivesse horário compatível com uma turma mais desejada para a seguinte.

Contudo, a solução adotada em 1983 (listas de opções conjuntas, isto é, pares de hospitais) corresponde, aqui, a pedir que os estudantes elaborem várias opções de grade horária (conjuntos de turmas). Fazê-lo a cada quadrimestre encarregaria os estudantes de um peso sobre-humano e poderia induzi-los a listar poucas opções, trazendo potencial congestão ao sistema.

Uma solução preliminar, em execuções experimentais da formulação acima, seria estimular ou requerer que o aluno "em fase" (isto é, seguindo a matriz curricular sugerida) liste as disciplinas competentes em certa ordem.

Outra, mais apropriada, pode ser o não congelamento das matrículas realizadas em etapas anteriores, com a aplicação do algoritmo Roth-Vande Vate para retornar a tais etapas e refazer a alocação dos alunos rejeitados, procurando eliminar instabilidades. 
Antes da execução do algoritmo, vale notar, podem ser acomodadas situações de emergência, matriculando diretamente e descontando os totais de vagas nas turmas, ou remodelando as preferências da instituição. 